\title{
Kelayakan Kapasitas Produksi Dengan Metode Rough Cut Capacity (RCCP) Di Seksi Ppm\#6, PT. Indah Kiat Pulp And Paper, Tbk.
}

\author{
St Nova Meirizha ${ }^{1)}$, Elman Syukur ${ }^{2)}$ \\ Program Studi Teknik Industri Universitas Muhammadiyah Riau \\ Jalan Tuanku Tambusai Ujung, Simpang Komersil Arengka (SKA), Kecamatan Tampan, \\ Kelurahan Delima, Delima, Kota Pekanbaru, Riau 28291 \\ Email : Novameirizha@umri.ac.id, Elman.zalukhu@gmail.com
}

\begin{abstract}
PT. Indah Kiat Pulp And Paper, Tbk is a company engaged in manufacturing that produces pulp and paper. One of the departments that produces paper (paper) is PPM \# 6. In this department, PPM \# 6 is one of the biggest machines in Indah Kiat Perawang. So many export orders were delegated to PPM department \# 6. As for the production process of export rollers, there are many obstacles such as the accumulation of export rollers on conveyors and several work stations, resulting in loss time and not achieving the target production requirements at the MPS (Master Product Schedule). To anticipate the problem of stacking the export rollers at several work stations, a capacity feasibility analysis is carried out for the existing equipment in PPM line \# 6. Capacity feasibility analysis uses rough cut capacity planning (RCCP) tools with the bill of labor (BOLA) method. The BOLA method shows the total capacity for each work station in PPM \# 6. From the observations, it can be concluded that for Wrapping work stations and paper machines it is not feasible to meet the production needs of MPS, while for winder, thimon and roll handling stations experience production shortages. Improvements that can be done are by revising the MPS, transferring the production of export rollers to the local order (finishing or converting order) and increasing the number of machines.
\end{abstract}

Keywords: Bill of Labor, RCCP, stacking rollers, capacity worthiness.

\begin{abstract}
Abstrak
PT. Indah Kiat Pulp And Paper, Tbk adalah sebuah perusahaan yang bergerak dalam bidang manufacture yang memproduksi pulp and paper. Salah satu departemen yang memproduksi paper (kertas) adalah PPM\#6. Pada depertemen ini, PPM\#6 merupakan salah satu mesin terbesar yang berada di Indah Kiat Perawang. Sehingga banyak oreder ekspor yang dilimpahkan ke departemen PPM\#6. Adapun dalam proses produksi rol ekspor banyak mengalami hambatan seperti terjadi penumpukan rol ekspor pada konveyor dan bebrapa stasiun kerja, akibatnya terjadi loss time dan tidak tercapainya target kebutuhan produksi pada MPS (Master Product Schedule). Untuk mengantisipasi masalah penumpukan rol eksport pada beberapa stasiun kerja, maka dilakukan analisis kelayakan kapasitas untuk stasin yang ada di line PPM\#6. Analisis kelayakan kapasitas menggunakan tools rough cut capacity planning (RCCP) dengan metode bill of labor (BOLA). Metode BOLA menunjukkan jumlah kapasitas untuk setiap stasiun kerja yang ada di PPM\#6. Dari hasil pengamatan, dapat disimpulkan bahwa untuk stasiun kerja Wrapping dan paper machine tidak layak untuk memenuhi kebutuhan produksi dari MPS, sedangkan untuk stasiun winder, thimon and roll handling mengalami kekurangan produksi. Perbaikan yang bisa dilakukan adalah dengan melakukan revisi MPS, melakukan pengalihan produksi rol ekspor keorder lokal (order finishing or converting) dan penambahan jumlah mesin.
\end{abstract}

Kata kunci : Bill Of Labor, RCCP, penumpukan rol, kelayakan kapasitas. 


\section{Pendahuluan}

\section{Latar Belakang}

PT Indah Kiat Pulp and Paper Tbk (IKPP) Perawang adalah salah satu perusahan industri manufacture yang cukup berkembang pesat pada saat ini. Industri manufacture PT. IKPP memiliki produk berupa bubur kertas ( $p u l p$ ) dan kertas (paper). Perusahaan industri yang berlokasi di daerah kecamatan Tualang, kelurahan Perawang, Kabupaten Siak.

IKPP merupakan salah satu perusahaan yang mengekspor kertas terbesar didunia. Bagian departemen yang memproduksi rol ekspor kertas salah satunya adalah seksi PPM\#6.

Dibalik besarnya PPM\#6, terdapat beberapa kendala dalam berproduksi. Salah satu kendala yang terjadi di PPM\#6 adalah ketika terjadi permintaan produksi dalam jumlah yang besar, sementara jangka waktu yang diberikan oleh costumer sangat singkat dan harus tepat waktu. Ketika hal ini terjadi, pihak perusahaan harus melakukan berbagai upaya agar tidak terjadinya penumpukan order dan complaint dari costumer karena adanya keterlambatan proses produksi. Terjadinya penumpukan produksi terjadi disebabkan oleh tingginya permintaan, sementara kapasitas mesin yang tersedia terbatas dengan total produksi yang hanya memiliki kapasitas standart. Apabila hal ini terjadi maka proses antrian penumpukan rol ekspor dibeberapa stasiun kerja akan terjadi, yang mengakibatkan terjadinya penurunan produksi, sehingga berakibat menyebabkan penurunan speed pada stasiun mesin yang sebelumnya atau bahkan melakukan stop mesin, demi menghindari tidak terjadinya penumpukan dan antrian produksi yang lebih panjang.

Berikut data pada periode agustus 2016 yang terjadi akibat penumpukan rol ekspor:

Tabel.1

Data Loss Time Akibat Penumpukan Rol Ekspor

\begin{tabular}{|c|c|c|c|}
\hline No & Date & $\begin{array}{c}\text { Lost Time } \\
\text { (menit) }\end{array}$ & Reason \\
\hline 1 & $8 / 8 / 2016$ & 125 & Empety spool \\
\hline 2 & $9 / 8 / 2016$ & 85 & Empety spool \\
\hline 3 & $10 / 8 / 2016$ & 135 & Empety spool \\
\hline 4 & $1 / 11 / 1900$ & 168 & Empety spool \\
\hline
\end{tabular}

Sumber: administrasi PPM\#6

Berdasarkan uraian di atas, maka dilakukan penelitian dengan judul "Analisis Kelayakan Kapasitas Produksi Dengan Menggunakan Metode Rough Cut Capacity Planning (RCCP)".

\section{Tinjauan Literatur}

\section{A. Perencanaan Kapasitas}

Agar perusahaan dapat berproduksi secara efisien dan efektif maka perusahaan harus menerapkan fungsi perencanaan kapasitas produksi. Kapasitas (capacity) adalah hasil produksi (throughtphut), atau jumlah unit yang dapat ditahan, diterima, disimpan, atau diproduksi oleh sebuah fasilitas dalam suatu periode waktu tertentu. Kapasitas adalah kemampuan pembatas dari unit produksi untuk berproduksi dalam waktu tertentu, dan biasanya dinyatakan dalam bentuk keluaran (output) per satuan waktu.

\section{B. Metode Rough Cut Capacity Planning (RCCP)}

[1] menerangkan peranan Rough Cut Capacity Planning (RCCP) pada sistem produksi planning and control sebagai "perencanaan produksi dan persediaan (inventory) adalah proses yang berkaitan dengan bagaimana mengatur fleksibilitas sumber daya untuk memenuhi kebutuhan konsumen dan untuk mendapatkan proses manufaktur yang stabil serta menentukan jumlah persediaan untuk mengatasi ketidak sesuaian yang terjadi”.

Proses ini melibatkan pelaksanaan dari tiga fungsi secara efektif:

1. Membuat MPS yang achievable

2. Merencanakan dan mengontrol kualitas

3. Merencanakan dan mengontrol kapasitas.

\section{Teknik Perhitungan RCCP}

Ada 3 teknik untuk merubah kuantitas MPS dari unit yang diproduksi menjadi jumlah waktu yang diperlukan untuk sumber daya tertentu [2], yaitu :

1. Capacity Planning Using Overall Factor (CPOF)/Perencanaan Kapasitas dengan Menggunakan Semua Faktor.

a. Membutuhkan tiga input : MPS, total waktu yang diperlukan untuk membuat sebuah produk (Ws), waktu yang diperlukan untuk membuat sebuah produk pada tiap sumber daya/departemen/work center.

b. Membutuhkan data yang tidak terlalu detil dan proses perhitungan paling mudah.

2. Bill Of Labor (BOLA)

Bill of labor adalah daftar jumlah tenaga kerja/waktu yang dibutuhkan untuk 
membuat sebuah item produk [3].

a. Membutuhkan input : MPS dan waktu standar dari tiap sumber yang dinyatakan dalam bentuk Bill of Labor. Dimana waktu standar : waktu yang dibutuhkan rata-rata pekerja untuk memproduksi 1 unit pada kondisi normal (sudah mempertimbangkan allowance).

b. Perhitungan kebutuhan kapasitas dilakukan dengan cara mengalikan : jumlah kuantitas pada MPS x waktu yang diperlukan tiap sumber daya/work center pada Bill Of Labor.

\section{Resource Profile}

Resource Profile adalah membagi

kebutuhn tenaga kerja berdasarkan waktu.

Tiap bill of labor harus dipecah berdasarkan waktu jika menggunakan pendekatan resource profile Perhitungan kapasitas, dengan metode resurce profile

memerlukan input:

a. Input perhitungan kebutuhan kapasitas dengan resource profile dan MPS,

b. Perhitungan kapasitas dilakukan dengan mengalikan resource profile dengan MPS

[4] Metode resorce profile merupakan teknik perhitungan RCCP yang paling detail dan perhitungannya paling sulit. Delam penggunaan metode resource profile baik digunakan untuk lingkungan: lead time untuk membuat produk sangat lama dan menggunakan sistem lot sizenya adalah lot for lot.

\section{Utilitas}

[5] Utilitas (U) digambarkan sebagai perbandingan antara jam pemanfaatan (aktual), atau perbandingan jumlah unit yang dihasilkan (kapasitas). Makin rendah tingkat utilitas suatu falitas, berarti makin tinggi waktu menganggur (idle time $=\mathrm{v}$ ), atau dapat dituliskan dengan rumus $\mu=1-v$. Angka utilisasi tidak boleh lebih kecil dari 1,0 (100\%).

\section{Efiensi}

Efisiensi (EFF) merupakan ukuran jumlah input yang digunakan dalam penghasilan sejumlah output tertentu, makin tinggi tingkat efisiensi, berarti semakin sedikit jumlah input digunakan dalam menghasikan output. Faktor efisiensi dapat lebih besar dari 1.

\section{Revisi MPS}

Revisi MPS dilaksanakan karena terjadinya kebutuhan yang terpakai melebihi dari kebutuhan yang tersedia, sehingga dilakukan beberapa cara untuk memperbaiki MPS tersebut. Salah satunya dengan menyeimbangkan beban kerja pada stasiun kerja. Cara ini sma sekali mengeluarka biaya. Cara lainnya adalah dengan melakukan over time, menambah shift kerja, menambah pekerja, dan subkontrak.

Jika langkah tersbut juga tidak dapat memperbaiki MPS tersebut, maka akan dilakukan tahapan revisi MPS. Jika pengunduran, over time, menambah shift kerja, menambah mesin, menambah pekerja dan subkontrak tidak dapat menetukan kapasitas yang memadai, maka perbaikan MPS sabagai usaha terakhir yang harus dilakukan. Penting untuk bahwa ketika terjadi kelebihan kapasitas yang tak terhindarkan, maka hal itu harus dikoreksi. Jika ada kapasitas yang tidak cukup maka tidak mungkin menyelesaikan pesanan tepat waktu. Pilihan kita adalah mempunyai menejemen yang mamutuskan apakah pesanan akan terlambat tergantung pada seluruh perusahaan atau perkarja dari suatu departemen. Pihak manjemen harus bertanggung jawab untuk melihat apakah RCCP dilaksanakan atau tidak.

\section{Tujuan Penelitian}

Tujuan dari penelitian ini adalah :

1. Menghitung kapasitas yang tersedia di setiap stasiun kerja,

2. Menghitung kapasitas yang dibutuhan

\section{Metodologi Penelitian}

Langkah-langkah pemecahan permasalahan penelitian ini, dijelaskan pada flowchart berikut:

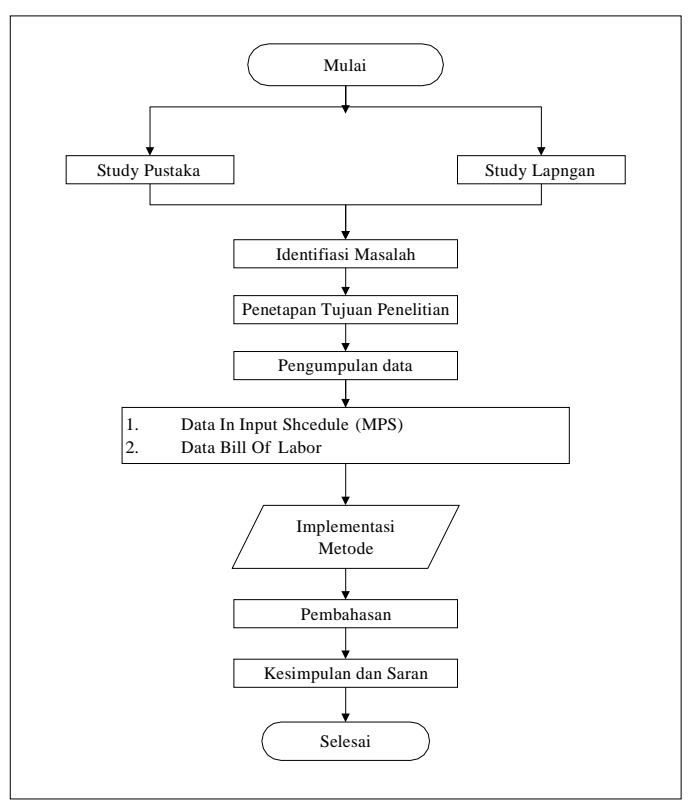


Gambar 1. Flowcart Metodologi Penelitian

\section{Hasil Dan Pembahasan}

\section{Pengumpulan Data}

Untuk menentukan kelayakan kapasitas pada paper machine \#6 (PPM\#6), maka diperlukan data MPS selama periode bulan Januari hingga Desember 2016. Berikut data MPS periode tersebut :

Tabel.2

Data MPS

\begin{tabular}{|r|l|c|c|c|}
\hline No & Bulan & $\begin{array}{c}\text { Hari Kerja } \\
\text { (Waktu) }\end{array}$ & $\begin{array}{c}\text { Target Per Hari } \\
\text { (Ton) }\end{array}$ & $\begin{array}{c}\text { Per Bulan } \\
\text { (Ton) }\end{array}$ \\
\hline 1 & Januari & 31 & 1200 & 37200 \\
\hline 2 & Februari & 28 & 1200 & 33600 \\
\hline 3 & Maret & 31 & 1200 & 37200 \\
\hline 4 & April & 30 & 1200 & 36000 \\
\hline 5 & Mei & 31 & 1200 & 37200 \\
\hline 6 & Juni & 30 & 1200 & 36000 \\
\hline 7 & Juli & 31 & 1200 & 37200 \\
\hline 8 & Agustus & 31 & 1200 & 37200 \\
\hline 9 & September & 30 & 1200 & 36000 \\
\hline 10 & Oktober & 31 & 1200 & 37200 \\
\hline 11 & November & 30 & 1200 & 36000 \\
\hline 12 & Desember & 31 & 1200 & 37200 \\
\hline
\end{tabular}

Sumber : Data Sekunder MPS PPM\#6

Data MPS tersebut dikerjakan selama setiap stasiun kerja,

Pengolahan Data

1. Kapasitas yang tersedia

Untuk menguji kelayakan kapasitas, maka perlu dilakukan penentuan terhadap jumlah kapasitas yang tersedia pada masing-masih stasiun kerja dalam satu bulan per periode. Berikut kapasitas tersedia pada bulan Januari periode 2016:

Kapasitas tersedia $=$ jumlah $\operatorname{mesin} /$ man power $\mathrm{x}$ jumlah shift $\mathrm{x}$ jam kerja $\mathrm{x}$ jumlah hari kerja $\mathrm{x}$ utilitas $\mathrm{x}$ efisiensi

1. Kapasitas tersedia (PM)

$=1 \times 3 \times 8 \times 31 \times 0.93 \times 0.90 \times$

$=622.728 \mathrm{jam}$

2. Kapasitas tersedia Winder (WI)

$=2 \times 3 \times 8 \times 31 \times 0.93 \times 0.90$

$=1245.456 \mathrm{jam}$

Tabel 5.

Data Kapasitas Tersedia Per Stasiun Kerja Periode 2016 REKAPTILLASI KAPASTIAS TERSEDIA BULANJANUARI-DESEMBR (JAM)

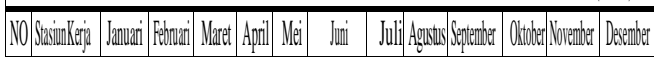

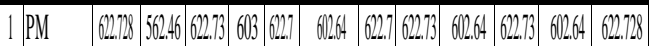

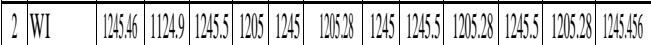

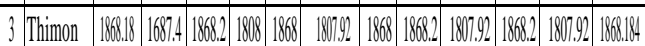

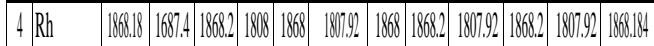

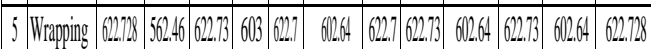

Sumber : Pengolahan Data MPS PPM\#6, 2016

2. Kapasitas Yang Dibutuhkan

Berikut kapasitas yang dibutuhkan untuk januari periode 2016 :

Kebutuhan kapasitas distasiun kerja adalah:

$\mathrm{PM}=$ Bill of labor $\mathrm{x}$ MPS bulan januari

1. $\mathrm{PM}=1 \mathrm{jam} /$ unit $\mathrm{x} 37200$ unit $=37200$ unit

Tabel 6.

Data Kebutuhan Kapasitas Per Stasiun Kerja Periode 2016

\begin{tabular}{|c|c|c|c|c|c|c|c|c|c|c|c|c|}
\hline \multirow{3}{*}{ id SK } & \multicolumn{12}{|c|}{ Kapasitas Dibutuhkan (TON) } \\
\hline & URRI & FERPNAN | & MARET & APRLL & MEl & JUNI & JULI & Gossus & EPTERB & 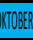 & HOVEB: & DESENBSER \\
\hline & 37200 & 33600 & 37200 & 36000 & 37200 & 36000 & 37200 & 37200 & 36000 & 37200 & 3000 & 37200 \\
\hline PM & 32200 & 33600 & 37200 & 36000 & 37200 & 36000 & 37200 & 37200 & 36000 & 37200 & 30000 & 36000 \\
\hline WI & 9300 & 8400 & 9300 & 9000 & 9300 & 9000 & 9300 & 9300 & 9000 & 9300 & 9000 & 9000 \\
\hline Thimon & 1860 & 1680 & 1860 & 1800 & 1800 & 1800 & 1860 & 1860 & 1800 & 1800 & 1800 & 1860 \\
\hline Rh & 1116 & 1008 & 11116 & 1080 & 1116 & 1080 & 1116 & 1116 & 1080 & 1116 & 1080 & 1116 \\
\hline & 2976 & 2688 & 2976 & 2880 & 2976 & 2880 & 2976 & 2976 & 2880 & 2976 & 2880 & 2976 \\
\hline
\end{tabular}

Sumber : Pengolahan Data MPS PPM\#6, 2016

\subsection{Tahap Analyze}

Berikut data seslisih antara kapasitas tersedia dengan kebutuhan kapasitas rata-rata dalam satu periode 2016

Tabel 7.

Data Rekapitulasi Selisih Rata-Rata Per Periode 2016

\begin{tabular}{|l|l|c|c|c|c|}
\hline No & $\begin{array}{c}\text { Stasiun } \\
\text { Kerja }\end{array}$ & $\begin{array}{c}\text { Rata-Rata Kapsitas } \\
\text { Kebutuhan Periode 2016 } \\
(\text { Jam) }\end{array}$ & $\begin{array}{c}\text { Rata-Rata Kapasitas } \\
\text { Tersedia Periode 2016 } \\
(\text { Jam) }\end{array}$ & Selisi (Jam) & $\begin{array}{c}\text { Persen Low } \\
\text { Capacity (\%) }\end{array}$ \\
\hline 1 & $\mathrm{Pm}$ & 36400 & 33606 & 2794 & 7.677189 \\
\hline 2 & $\mathrm{Wi}$ & 9100 & 9532 & -432 & -4.74366 \\
\hline 3 & $\mathrm{~T}$ himon & 1825 & 2016 & -191 & -10.4834 \\
\hline 4 & Rh & 1095 & 2016 & -921 & -84.139 \\
\hline 5 & Wrapping & 2920 & 672 & 2248 & 76.98453 \\
\hline
\end{tabular}

Sumber : Pengolahan Data MPS PPM\#6, 2016

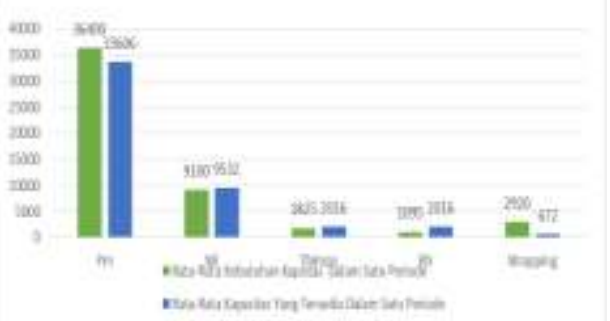

Gambar. 2 Diagram Perbedaan Selisih Kebutuhan Kapasitas Dengan Kapasitas Tersedia Periode 2016

3. Melakukan uji kelayakan kapasitas. sebulan penuh untuk setiap bulannya. Untuk sistem kerjanya adalah sebagai berikut :

1. Jumlah shift per hari $(\mathrm{S})=3 \mathrm{shift} / \mathrm{hari}$

2. Jam kerja per shift $(\mathrm{H})=8 \mathrm{jam} / \mathrm{shift}$. Untuk menunjang pekerjaan yang telah ditetapkan pada MPS, maka beberapa stasiun kerja yang digunakan adalah sebagai berikut : 
Tabel 8.

Data Stasiun Kerj

\begin{tabular}{|c|l|c|}
\hline No & \multicolumn{1}{|c|}{ Stasiun kerja } & Jumlah mesin \\
\hline 1 & Paper Machine (PM) & 1 \\
\hline 2 & Winder (WI) & 2 \\
\hline 3 & Thimon & 3 \\
\hline 4 & R0ll Handling (RH) & 3 \\
\hline 5 & Wrapping & 1 \\
\hline
\end{tabular}

Sumber : Data Sekunder MPS PPM\#6

Dalam perhitungan kelayakan kapasitas juga perlukan adanya data bill of labor dari stasiun kerja. Waktu yang diperlukan untuk masingmasing stasiun kerja dapat dilihat tabel berikut : Keterangan :

Tabel 9.

Bill Of Labor

\begin{tabular}{|c|l|c|c|}
\hline No & $\begin{array}{c}\text { Stasiun } \\
\text { Kerja }\end{array}$ & $\begin{array}{c}\text { Kebutuhan Waktu } \\
\text { Per Produk (Jam) }\end{array}$ & $\begin{array}{c}\text { Jumlah } \\
\text { Roll }\end{array}$ \\
\hline 1 & PM & 1 & 1 \\
\hline 2 & WI & 0.25 & 7 \\
\hline 3 & Thimon & 0.05 & 1 \\
\hline 4 & Rh & 0.03 & 1 \\
\hline 5 & Wrapping & 0.08 & 1 \\
\hline
\end{tabular}

Sumber : Data Sekunder MPS PPM\#6

Dari hasil pengolahan data, maka didapat bahwa untuk kapasitas PM dan Wrapping mengalami kekurangan kapasitas yaitu:
PM
$=7,67 \%$
Wrapping
$=76,98 \%$

\section{Tahap Improve}

Rekomendasi yang bisa dilakukan adalah :

1. Revisi MPS (Master Produk Schedule), yaitu dengan mengurangi rencana produksi,

2. Melakukan pengalihan produksi keorder lokal (order yang berupa big sheet yang menjadi order lokal), untuk menghindari penumpukan rol eksport,

3. Penambahan jumlah mesin, yaitu sebagai alernatif terakhir yang bisa diambil oleh perusahaan.

\section{Simpulan}

Berdasarkan dari hasil pengolahan dan analisa data dengan menggunakan Rough Cut Capacity Planning dengan metode bill of labour untuk proses pembuatan kertas dari paper machine hingga dikirim pada selesai proses wrapping di PPM\#6, maka dapat diperoleh kesimpulan sebagai berikut:

1. Dari hasil perhitungan kapasitas produksi PPM\#6, khususnya untuk produksi orderan rol ekspor, maka didapat kapasitas yang

2. Kapasitas yang dibutuhkan pada stasiun kerja di PPM\#6 sebagai berikut: tersedia untuk setiap stasiun sebagai berikut: Tabel 10.

Data Rata-Rata Kapasitas Tersedia Per Periode 2016

\begin{tabular}{|c|l|c|}
\hline No & \multicolumn{1}{|c|}{ Stasiun Kerja } & $\begin{array}{c}\text { Rata-Rata Kapasitas Tersedia Peride Periode 2016 } \\
\text { (Jam) }\end{array}$ \\
\hline 1 & PM & 33606 \\
\hline 2 & WI & 9532 \\
\hline 3 & Thimon & 2016 \\
\hline 4 & Rh & 2016 \\
\hline 5 & Wrapping & 672 \\
\hline
\end{tabular}

Sumber : Pengolahan Data MPS PPM\#6, 2016

yang tersedia dengan kapasitas kebutuhan sebagai berikut:

Tabel 11.

Data Rekapitulasi Selisih Rata-Rata Per Periode 2016

\begin{tabular}{|c|l|c|c|c|c|}
\hline No & $\begin{array}{c}\text { Stasiun } \\
\text { Kerja }\end{array}$ & $\begin{array}{c}\text { Rata-Rata Kapsitas } \\
\text { Kebutuhan Periode 2016 } \\
(\text { Jam) }\end{array}$ & $\begin{array}{c}\text { Rata-Rata Kapasitas } \\
\text { Tersedia Periode 2016 } \\
\text { (Jam) }\end{array}$ & Selisin (Jam) & $\begin{array}{c}\text { Persen Low } \\
\text { Capacity (\%) }\end{array}$ \\
\hline 1 & Pm & 36400 & 33606 & 2794 & 7.677189 \\
\hline 2 & Wi & 9100 & 9532 & -432 & -4.74366 \\
\hline 3 & Thimon & 1825 & 2016 & -191 & -10.4834 \\
\hline 4 & Rh & 1095 & 2016 & -921 & -84.139 \\
\hline 5 & Wrapping & 2920 & 672 & 2248 & 76.98453 \\
\hline
\end{tabular}

Sumber : Pengolahan Data MPS PPM\#6, 2016

Maka dari data diatas disimpulkan bahwa untuk stasiun PM dan Wrapping mengalami kekurangan kapasitas.

3. Dari hasil uji kelayakan uji kapasitas, maka didapat perbedaan selisih antar kapasitas

Tabel 11.

Data Rekapitulasi Selisih Rata-Rata Per Periode 2016

\begin{tabular}{|c|l|c|}
\hline No & $\begin{array}{l}\text { Stasiun } \\
\text { Kerja }\end{array}$ & $\begin{array}{c}\text { Rata-Rata Kapasitas Tersedia Peride } \\
\text { Periode } \\
\text { 2016 (Jam) }\end{array}$ \\
\hline 1 & PM & 33606 \\
\hline 2 & WI & 9532 \\
\hline 3 & Thimon & 2016 \\
\hline 4 & Rh & 2016 \\
\hline 5 & Wrapping & 672 \\
\hline
\end{tabular}

Sumber : Pengolahan Data MPS PPM\#6, 2016

Selain saran yang telah direkomendasikan untuk perbaikan, beberapa saran yang lain nya dapat diberikan :

1. Diharapkan perusahaan untuk segera melakukan revisi MPS atau meningkatkan kapasitas mesin untuk menghindari terjadinya overload dan kekurangan kapasitas sehingga terjadinya penambahan cost yang tak terduga.

2. Diharapkan bagi mahasiswa lain yang melakukan kerja pratik dengan mengambil studi kasus yang sama dengan penelitian ini, agar dapat mencari metode yang lain 
yang lebih lengkap untuk pemecahan masalah di Lapangan.

\section{Daftar Pustaka}

SURYA TEKNIKA Vol. 6 No. 1, Desember 2019: 1-7
[1] Fogarty, Donald W., dkk.1991. Production and Inventory Management. Ohio : SoutWestern Publishing Co.

[2] Kusuma, Hendra. 2004. Manajemen Produksi, Perencanaan dan pengendalian Produksi. Yokyakarta: Andi.

[3] Modul Pratikum. 2016. Sistem produksi. Teknik industri. Universitas Muhammadiyah Riau 
[4] Nasution, Araman Hakim. 1999. Perencanaan Produksi dan Pengenalian Produksi. Guna Widya : Jakarta.

[5] Sinulingga , Sukaria. 2009. Perencanaan dan pengendalian Produksi. Cetakan pertama. Yokyakarta: Graha Ilmu. 